 \\ SCIENTIFIC COMMITTEE \\ SEVENTEENTH REGULAR SESSION
}

Electronic Meeting

11-19 August 2021

Tori lines mitigate seabird bycatch in a pelagic longline fishery

WCPFC-SC17-2021/EB-IP-05

E. Gilman ${ }^{1}$, M. Chaloupka ${ }^{2}$, A. Ishizaki ${ }^{3}$, M. Carnes ${ }^{4}$, H. Naholowaa ${ }^{3}$,

C. Brady ${ }^{5}$, S. Ellgen ${ }^{5}$, and E. Kingma ${ }^{6}$

\footnotetext{
${ }^{1}$ Pelagic Ecosystems Research Group, Honolulu, USA

${ }^{2}$ Ecological Modelling Services Pty Ltd \& Marine Spatial Ecology Lab, University of Queensland, Brisbane, Australia

${ }^{3}$ Western Pacific Regional Fishery Management Council, Honolulu, USA

4 'Ike Solutions, Honolulu, United States

${ }^{5}$ Pacific Islands Regional Office, National Marine Fisheries Service, Honolulu, USA

${ }^{6}$ Hawaii Longline Association, Honolulu, USA
} 


\title{
Tori lines mitigate seabird bycatch in a pelagic longline fishery
}

\author{
Eric Gilman (D) Milani Chaloupka (1) - Asuka Ishizaki • Matthew Carnes • \\ Hollyann Naholowaa $\cdot$ Colby Brady $\cdot$ Sarah Ellgen $\cdot$ Eric Kingma
}

Received: 26 February 2021/Accepted: 27 April 2021

(C) The Author(s), under exclusive licence to Springer Nature Switzerland AG 2021

\begin{abstract}
Albatross bycatch has been increasing over the past decade in the US tuna longline fishery of the central North Pacific. A controlled field experiment was used to assess the efficacy of bird scaring or tori lines as a seabird bycatch mitigation measure for this fishery in a 3-factor sampling design with other mitigation methods (blue-dyed bait, offal discharge). A multilevel geoadditive Bayesian regression modeling approach was used to assess 3 albatross-gear interaction metrics (attempted contacts, contacts,
\end{abstract}

Supplementary Information The online version contains supplementary material available at https://doi.org/10.1007/ s11160-021-09659-7.

E. Gilman $(\bowtie)$

Pelagic Ecosystems Research Group, Honolulu, USA

e-mail: FisheriesResearchGroup@gmail.com

M. Chaloupka

Ecological Modelling Services Pty Ltd \& Marine Spatial

Ecology Lab, University of Queensland, Brisbane,

Australia

A. Ishizaki · H. Naholowaa

Western Pacific Regional Fishery Management Council,

Honolulu, USA

M. Carnes

Joint Institute for Marine and Atmospheric Research,

University of Hawaii, Honolulu, USA

Present Address:

M. Carnes

'Ike Solutions, Honolulu, United States captures) recorded for each longline set using an electronic monitoring system. We found albatross contacts with baited hooks were ca. 3 times (95\% highest posterior density interval [HDI] 1-7) less likely for sets equipped with tori lines rather than without tori lines. Attempts to contact baited hooks were ca. 2 times (95\% HDI 1-4) less likely for tori line-equipped sets. Albatrosses were also less likely to be captured in tori line sets but captures were too few to support strong inference compared with the contact rates. Tori lines were therefore found to be an effective management measure to mitigate albatross interactions in this fishery. Offal discharge during setting,

\author{
C. Brady · S. Ellgen \\ Pacific Islands Regional Office, National Marine Fisheries \\ Service, Honolulu, USA \\ E. Kingma \\ Hawaii Longline Association, Honolulu, USA
}


however, was associated with higher seabird interactions-but that inference was not strong since offal discharge and blue-dyed bait were confounded treatments in some sets. Nonetheless, it was apparent that neither offal discharge nor blue-dyed bait was helpful in reducing albatross interactions in this trial and so the efficacy of those measures warrants further experimental investigation.

Keywords Albatross - Bycatch - Electronic monitoring · Longline fisheries · Tori line · Bayesian modelling $\cdot$ Gaussian process

\section{Introduction}

Incidental capture or bycatch in commercial fisheries is considered a major threat to the global conservation of pelagic seabirds (Anderson et al. 2011; Gray and Kennelly 2018). This is particularly the case for albatrosses and petrels, which are two of the three most threatened groups of seabirds (Dias et al. 2019). Of 29 albatross and large petrel species listed under the Agreement on the Conservation of Albatrosses and Petrels (ACAP), 19 are categorized as threatened by the IUCN (Phillips et al. 2016; International Union for the Conservation of Nature 2021). It has been estimated recently that at least 160,000 seabirds are killed annually in pelagic longline fisheries, of which a large proportion are albatrosses and the large petrel species (Anderson et al. 2011). Hence a range of gear technologies have been proposed to help mitigate seabird bycatch in pelagic longline fisheries such as night setting, branchline weighting, bird curtains, side setting, blue-dyed bait, strategic offal discharge, underwater setting devices, hook shielding devices, and bird-scaring or tori lines (Gilman et al. 2005; ACAP 2019).

A tori line, initially developed by Japanese tuna longline fishers (Brothers et al. 1999), is a line with streamers that is towed from the stern of the vessel as crew set baited hooks. The forward movement of the fishing vessel creates drag on the streamer line, so that a section of the line is in the air above the sea surface. This aerial portion of the streamer line, as the name suggests, can have streamers attached at various intervals to contribute to discouraging seabirds from attacking baited hooks.
The five tuna regional fisheries management organizations (RFMOs) have measures in place that either require or include tori lines as a seabird bycatch mitigation option in designated areas (International Commission for the Conservation of Atlantic Tunas 2011; IATTC 2012; IOTC 2012; WCPFC 2018; CCSBT 2020). Tori lines are also prescribed for use in combination with other measures by ACAP (2019). Some nations such as Japan, Uruguay, New Zealand and South Africa, require tori line use in pelagic longline fisheries (Japan Ministry of Agriculture, Forestry and Fisheries 2008; Uruguay Direccion Nacional de Recursos Acuqticos 2015; South Africa Department of Agriculture, Forestry and Fisheries 2019; New Zealand Ministry for Primary Industries 2020).

Seabird bycatch of the US central North Pacific tuna longline fishery comprised mainly Laysan (Phoebastria immutabilis) and black-footed albatrosses $(P$. nigripes), which are categorized as Near Threatened with stable and increasing population trends, respectively (International Union for the Conservation of Nature 2021). Albatross bycatch has been increasing over the past decade in this fishery (Gilman et al. 2016; WPRFMC 2020). This trend is attributable to increasing fishing effort and an increase in the number of albatrosses attending the vessels. The latter is possibly in response to variability in ocean productivity linked to inter-annual and decadal climate cycles, and to the increasing population trend of black-footed albatrosses (Gilman et al. 2016; International Union for the Conservation of Nature 2021). Currently, a range of seabird bycatch mitigation measures, including the use of blue-dyed fish bait and strategic offal and bait discharge, are regulatory requirements in this fishery (Gilman et al. 2016).

Management authorities prioritized investigating whether tori lines would reduce seabird bycatch in this fishery, but the efficacy of this measure has not been rigorously evaluated for this high-value deep-set tuna fishery (WPRFMC 2020). Although tori lines are a commonly promoted seabird bycatch mitigation measure in pelagic longline fisheries around the world, there have been surprisingly few rigorous experimental assessments (Yokota et al. 2011; Melvin et al. 2013; Sato et al. 2016; Domingo et al. 2017; Jimenez et al. 2020). So, an experimental field trial using commercial pelagic longline vessels and a videobased electronic monitoring system was undertaken to 
evaluate whether tori lines might be an effective seabird mitigation measure for the US central North Pacific tuna longline fishery.

The findings from this study (1) contribute directly to the adoption of proven mitigation measures for the US central North Pacific pelagic longline fishery to support compliance with the US seabird bycatch regulatory requirements, and (2) demonstrate the capability of electronic monitoring systems for fisheries bycatch risk assessment.

\section{Methods}

Experimental design

The experimental field trial comprised 175 sets deployed during 17 trips from 4 commercial longline vessels undertaken between February and July 2020. Fig. S1 shows the central North Pacific study area overlaid on the estimated non-breeding range of the Laysan and black-footed albatrosses. Branchline weighting designs (45 g lead-centered swivels attached about $0.6 \mathrm{~m}$ from the hook), leader material (wire), bait (saury, Cololabis saira), hook type (15/0 circle hooks), time-of-day of setting (during the daytime) and the deck location of setting (from the conventional position at the stern, and not from the side) were the same for all sets.

Here the longline set is the fundamental sampling unit or blocking factor (Bergh et al. 1990; Jensen et al. 2018) that is nested within trip, which is itself nested within vessel. So, the sampling design comprises three crossed random-effects: set, trip and vessel. This multilevel or hierarchical random-effects structure needs to be accounted for in any statistical modeling of the estimated tori line effect on albatross bycatch rates. The trial also comprised two other co-applied seabird bycatch mitigation measures or treatments: (1) strategic discharge of offal and spent bait, and (2) blue-dyed fish bait (Gilman et al. 2016). The treatment used for the first set of a trip was randomly selected. The trial therefore comprised three treatments: (1) tori line, (2) offal/spent bait discharge and (3) blue-dyed bait. The 3-treatment experimental design is summarized in Fig. 1, which shows the $2^{3}=8$ possible treatment arms if this was a fully factorial study design.

Two of the eight arms were not possible here because, due to regulatory requirements, offal only occurred in conjunction with the blue-dyed bait treatment (Fig. 1), resulting in a partially nested or partially clustered experimental design (Baldwin et al. 2011; Candlish et al. 2018). The partially nested design adds a complication that needs to be accounted for in "any subsequent statistical modeling of the estimated tori line effect on seabird bycatch rates. This was done here by creating a 3-category factor cluster as follows: $1=$ [offal $==$ "no" \& blue $==$ "no", $2=[$ offal $==$ "no" \& blue $==$ "yes"], $3=$ [offal $==$ "yes" \& blue $==$ "yes"]. There was no level that included offal/bait discharge but not bluedyed bait. The data derived from this experiment were captured using the video-based electronic monitoring system.

Tori line deployment and design

Figures 2 and 3 show the tori line design used in the experiment. A $50 \mathrm{~m}$-long, red, $3 \mathrm{~mm}$ diameter, 12-strand, single-braid Dyneema (AmSteel AS-78 Dyneema, thermoplastic polyethylene) rope was used for the aerial section of the tori line. Two $50 \mathrm{~cm}$-long streamers were attached every $1 \mathrm{~m}$ along the aerial section, with the first streamer attached at $2.5 \mathrm{~m}$ from the point of attachment to the tori pole on the vessel deck, and the last streamer attached at $30.5 \mathrm{~m}$, for a total of 28 streamers. The aerial section was attached $5 \mathrm{~m}$ above the sea surface on schedule 40 , marine grade, stainless steel poles. Streamers were $50 \mathrm{~cm}$ long, $5 \mathrm{~cm}$-wide, $6 \mathrm{~mm}$ thick, black polyethylene sheeting. One $100 \mathrm{~cm}$-long strip was spliced through the Dyneema rope to create the two $50 \mathrm{~cm}$-long streamers (Fig. 3). The drag section of the tori line was $55 \mathrm{~m}$-long, and made of $6 \mathrm{~mm}$ diameter, 'Blue Steel' 12-strand polyolefin fiber rope. A weak link, using monofilament nylon (polyamide), was in between the aerial section of the tori line and the tori pole (see Pierre 2018; Goad 2017; Goad and Debski 2017). Safety lines were incorporated to retain the tori line if the weak link broke. When a vessel sets at $11.1 \mathrm{~km} / \mathrm{h}$ (6 knots), this would produce ca. $6.2 \mathrm{~kg}$ of drag, resulting in a $50 \mathrm{~m}$-long aerial section. The aerial and drag sections were connected by splicing them onto a $6 \mathrm{~mm}$ stainless steel swivel, which was covered first with heat shrink wrap and then with electrical tape.

This tori line design was selected to meet the minimum tori line design requirements of the two Pacific tuna RFMOs in whose convention areas the US 


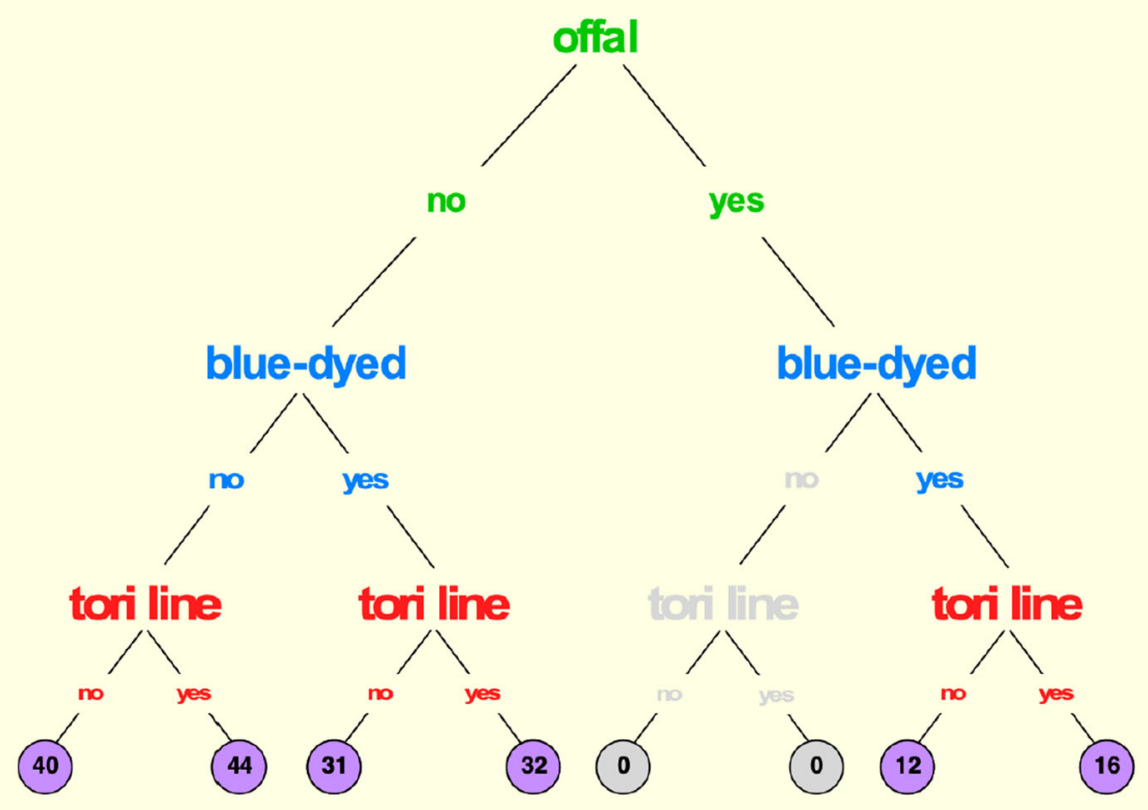

Fig. 1 Experimental design to evaluate the effect of tori lines as a seabird bycatch mitigation measure in Hawaii's tuna longline fishery given the co-application of two other mitigation measures (offal discard, blue-dyed bait). Terminal nodes show the number of sets completed for each of the $2^{3}=8$ potential

treatment combinations. Nodes with zero sets shows those treatment arms that did not occur in this study, due to regulatory requirements, and hence leads to a partially nested rather than a fully factorial study design. The seabird bycatch mitigation measure of branchline weighting was used in all treatments



Fig. 2 Bird-scaring tori line design, with $50 \mathrm{~m}$-long aerial section, $55 \mathrm{~m}$-long drag section, tori line attached $5 \mathrm{~m}$ above the sea surface, with two $50 \mathrm{~cm}$-long streamers attached every $1 \mathrm{~m}$

central North Pacific tuna longline fishery occurs (IATTC 2012; WCPFC 2018). Materials were selected based on preferences expressed by Hawaii longline fishers, local availability, cost and lessons learnt from tori line trials in New Zealand and Japan (Goad and Debski 2017; Katsumata et al. 2019). The selected tori line design was also based on the estimated distance astern that Laysan and black-footed albatrosses are able to access baited hooks. starting at $2.5 \mathrm{~m}$ from the point of attachment of the aerial section to a pole located on the vessel deck to $30.5 \mathrm{~m}$ along the aerial section

\section{Electronic monitoring system}

The electronic monitoring (EM) system included an 8-megapixel super low lux camera (GeoVision model GV-ABL8712) positioned to provide a field of view off the vessel stern. The camera was set to record at 20 frames per second and imagery at 1440 p resolution. Cameras were mounted inside of a setting shack from the roof or otherwise from another structure at the stern if available. The low lux sensors optimize the 




Fig. 3 A $100 \mathrm{~cm}$-long plastic strip was spliced through a Dyneema rope to create two $50 \mathrm{~cm}$-long streamers on the aerial section of the tori line

cameras' recording in low light conditions. The cameras had waterproof housings and a marine sealant was used to augment waterproofing.

Using that video-based system, the EM analyst collected the data fields and applied the data collection methods summarized in Table S1. The data fields are organized by categories of: seabird bycatch mitigation method, other gear and other fishing methods that potentially have significant effects on seabird catch, response variables of seabird attempts and contacts during the set, seabird scan counts, and environmental variables that potentially have significant effects on seabird catch. Covariates or predictors that explain seabird catch and survival risk were adapted from Gilman et al. (2014, 2016). The protocol for recording seabird attempts and contacts with baited hooks was adapted from Boggs (2001) and Gilman et al. (2003), and these data fields are defined in Table S1. The opensource EM reviewing software Review (Chordata 2019) was used to process the EM data.

\section{EM-derived data}

Nearly all recorded seabird interactions were for either the black-footed albatross or the Laysan albatross exposed to this pelagic longline fishery-shearwaters accounted for ca. $1 \%$ of attempts to contact baited hooks. The two albatross species records were combined into a single albatross category as there were insufficient data to estimate species-specific effects.

The 2 albatross-gear response metrics were: (1) the recorded number of albatross attempts to attack the gear/bait for each set, and (2) the recorded number of albatross contacts with the gear/bait for each set. There were too few attempts or contacts $>2$ or 3 to model meaningfully so these response metrics were more appropriately restructured as a binary or Bernoulli response $(0,1)$ variable with the attempt rate being recoded as either 0 for no attempts and 1 for one or more attempts. The same procedure was applied to the albatross contacts data.

There were only 5 Laysan and 5 black-footed albatross captures, based on the number observed retrieved during the gear haulback, which were too few to warrant a more comprehensive statistical analysis other than a modelled statistical summary. So, for this metric the median posterior albatross capture rate and highest posterior density interval (HDI) were summarised by sampling from a binomial likelihood with a Bayes-Laplace prior (Tuyl et al. 2008) using the binom $R$ package (Dorai-Raj 2014) — rather than merely using the raw or naïve capture summaries.

\section{Statistical modeling approach}

The statistical modeling approach for the two contact rate metrics was based on a Bayesian inference workflow (Gabry et al. 2019) using spatially-explicit generalized additive mixed regression structured models (geoGAMM: Fahrmeir and Lang 2001; Kammann and Wand 2003) with an appropriate responsespecific likelihood for the various forms of interaction rate data. The response metrics were binary data (for example: $0=$ no attempts, $1=$ at least one attempt to attack the gear/bait) and so were sampled from a Bernoulli probability distribution and so appropriately modelled using a regression model with Bernoulli likelihood-which is a special case of a binomial likelihood but now with a single trial (Congdon 2003).

Specifically, geoGAMMs with Bernoulli likelihood were fit to the albatross interaction data (attempt $=$ at least 1 albatross attempt to attack the gear, contact $=$ at least 1 albatross contact with the gear) while accounting for potentially informative predictors 
using the Stan computation engine (Carpenter et al. 2017) via the brms interface (Bürkner 2017). All models were implemented using weakly informative regularizing priors (Lemoine 2019) and so prior predictive graphical summaries were used to assess the adequacy of the priors used (Gabry et al. 2019).

The predictors included hooks per set (as a nonlinear effect rather than just as an offset: see Davies and Jonsen 2011 for discussion of nonproportional effort scaling), wind speed, cloudiness (overcast or not), 'offal blue-dyed bait' cluster, nonlinear mean density of seabirds attending the vessel and specific set geolocation. The offal-blue-dyed-bait cluster covariate helps account for the partially nested design issues summarized in Fig. 1.

Cubic smoothing splines (Wood 2006) were used to account for possible nonlinear functional form of the covariates such as hooks per set (the longline fishing effort metric). The structured spatial effect of the individual set geolocations was estimated in the geoGAMMs using a 2D Gaussian Process structure (Gelfand and Schliep 2016).

The random effect structures (intercepts-only) included in the geoGAMMs were the identity of the 17 trips and the identity of the 4 vessels to account for any correlated or trip- and/or vessel-specific heterogeneity in the interactions rates not accounted for by the other predictors. The 3-category cluster variable was included as either a fixed effect or a random effect-if as a random effect then this form was used as suggested by Candlish et al. (2018): ( $0+$ torilcluster), where tori indicates whether tori lines were used or not.

Model selection was based on leave-one-out crossvalidation metrics to estimate any comparative difference in expected predictive accuracy between the various models fitted such as whether to include an explicit spatial effect or not or whether including a vessel-specific random effect was necessary (Vehtari et al. 2017). The weight of evidence in favor of one model over any other candidate models was also assessed using Bayesian stacking, which is the Bayesian analogue of model averaging (Yao et al. 2018).

The posterior samples for all models were sourced from 4 chains and 12,000 iterations after a warmup of 2000 iterations per chain. Therefore, the posterior for each estimate comprised 10,000 samples or draws that were used to derive the uncertainty intervals (HDIs or highest posterior density intervals: Kruschke and Liddell 2018) using the tidybayes package for $\mathrm{R}$ (Kay 2020a). Convergence diagnostics such as effective posterior sample size and the Gelman-Rubin statistic (Rhat $<1.01$ ) reflected convergence of all Bayesian models used here (Gelman and Hill 2007). Further evaluation of the best-fit-model was then assessed using graphical posterior predictive checks (Gabry et al. 2019). All inference was then made using the best-fit model.

In any experimental setting it is important to be able conclude that there was an effect, when there really was an effect. This can be done using indices of existence and significance in a Bayesian setting (Makowski et al. 2019). A probability statement about the existence of a particular effect and its direction, such as tori line effects, can be determined with those 10,000 draws using the probability of direction metric proposed recently by Makowski et al. (2019) —also known as the maximum probability of an effect.

The significance (rather than just existence) of any such effect (or parameter estimate) was then assessed using the HDI + ROPE approach (Kruschke and Liddell 2018). The region of practical equivalence (ROPE) has been proposed as a robust procedure to determine the significance of a meaningful effect in a Bayesian setting using the posterior draws from the best-fit model along with the calculated $95 \%$ highest posterior density interval of those draws (Kruschke and Liddell 2018). An appropriate ROPE range or "null hypothesis" region for a regression model with Bernoulli likelihood has been defined by Kruschke and Liddell (2018) as [-0.18, 0.18].

The decision rule is that if the HDI lies entirely outside the ROPE then reject the "null hypothesis" that samples are the same or equivalent (Kruschke and Liddell 2018). If the HDI is lies entirely within the ROPE then accept the "null". Otherwise, the decision to reject or accept is "undecided". This is called the HDI + ROPE decision rule (Kruschke and Liddell 2018). Kelter (2020) suggested recently that using the entire posterior distribution (aka the full or $100 \%$ ROPE) could be used for a more robust decision. The existence and significance metrics were derived here using the Bayestest $\mathrm{R}$ package for $\mathrm{R}$ (Makowski et al. 2019).

Finally, the estimated effects summaries based on the best-fit conditional regression models were then adjusted for variable sample size of the treatments 
using the marginal means approach (Searle et al. 1980; Lenth 2016) and implemented using the emmeans package for R (Lenth 2020). These marginal mean effects were summarised as the median and the highest posterior density intervals $(80 \%, 95 \%)$ using the tidybayes package for $\mathrm{R}$ (Kay 2020a) and stat_halfeye() function from the ggdist package for R (Kay 2020b). The posterior ratio (and 95\% HDI) based on the 10,000 posterior samples for the 2 densities was then used to assess any apparent difference between the contact rate for sets deployed with or without tori lines. The posterior ratio summary was also included in the summary plot. The ggplots2 (Wickham 2016) and colorspace (Zeileis et al. 2020) packages for $\mathrm{R}$ were used for the summary graphics while the patchwork package for $\mathrm{R}$ (Pedersen 2020) was used for the multi-panel arrangements.

\section{Results}

Strong inference was possible using the Bayesian structured modeling workflow that comprised (1) prior predictive checks to assess the adequacy of the priors used for (2) a robust statistical model accounting for experimental design constraints and potential predictors of interaction rates other than the tori line treatment effect and then followed by (3) posterior predictive checks of the adequacy of the statistical model fitted to the interaction data. Of the potentially informative predictors for all the geoGAMMs fitted to the albatross interaction data, there was a significant seabird density effect, where albatross interaction rates increased nonlinearly with increasing seabird density, and model selection based on leave-one-out cross-validation (LOOcv) and the Bayesian stacking suggest that the spatial effect was a significant effect and had relevance for any model inference (Fig. S2). On the other hand, LOOcv and Bayesian stacking metrics suggested that inclusion of the vessel-specific random effects was not necessary but that trip-specific random effects were-but there was little difference in model fit using vessel, set and trip as random effects but the best-fit model included trip-specific effects only. So, the best-fit GAMMs selected for inference for either the attempt or contact rates excluded the vessel- and set- specific random-effects and used only trip-specific random-effects. The best-fit geoGAMMs identified by the LOOcv and Bayesian stacking metrics fitted the interaction data well as shown for example by the posterior predictive check tests summarized in Supplemental Material Fig. S3. All inference was based on those best-fit geoGAMMs and in all models the tori line treatment effect conditional on all other predictors was significant statistically.

Figures 4 and 5 show the existence and significance of the modelled conditional tori line effect based on the posterior draws from the best-fit contact rate geoGAMM. Specifically, Fig. 4 shows that the tori line effect had a 0.994 probability of being negative while Fig. 5 shows that the tori line effect can indeed be considered as statistically significant using either the full $(100 \%)$ HDI + ROPE or the 95\% HDI + ROPE metric, while the estimated offal-blue-dyedbait cluster-specific effects were equivocal although the specific 'offal $=$ yes + bluedye $=$ yes' effect had a 0.969 existence probability of being positive and hence associated with a higher contact rate rather than reducing the rate (Fig. 4).

For attempts (not shown), the tori line effect was similar to the results for contact rate, and had a 0.995 probability of being negative and was statistically significant using either the full $(100 \%)$ HDI + ROPE or the $95 \%$ HDI + ROPE metric. The estimated offalblue-dyed-bait cluster-specific effect was equivocal for the specific 'offal $=$ no + bluedye $=$ yes' effect but significant for the 'offal = yes + bluedye $=$ yes' effect that also had a 0.978 existence probability of being positive.

Figure 6 shows the estimated marginal means for the tori line effect for the albatross contact rate sourced from the posterior draws from the best-fit conditional geoGAMM. The top panel shows the estimated marginal means density distribution for the sets with and without tori lines where it is apparent that it was ca. 3 times (95\% HDI: 1-7) less likely to have one or more albatross contact when tori lines were deployed. The bottom panel summarizes the same predicted effect as in the top bottom but now the summary is conditioned on the offal-blue-dyed-bait cluster level. Again, contact rate is predicted to be lower on sets with tori lines deployed and that this effect difference increases with 1 or 2 co-applied mitigation measures-contact rates were highest when the sets were deployed with both offal and blue-dyed bait but that co-application of tori lines for those sets moderated that undesirable effect. 


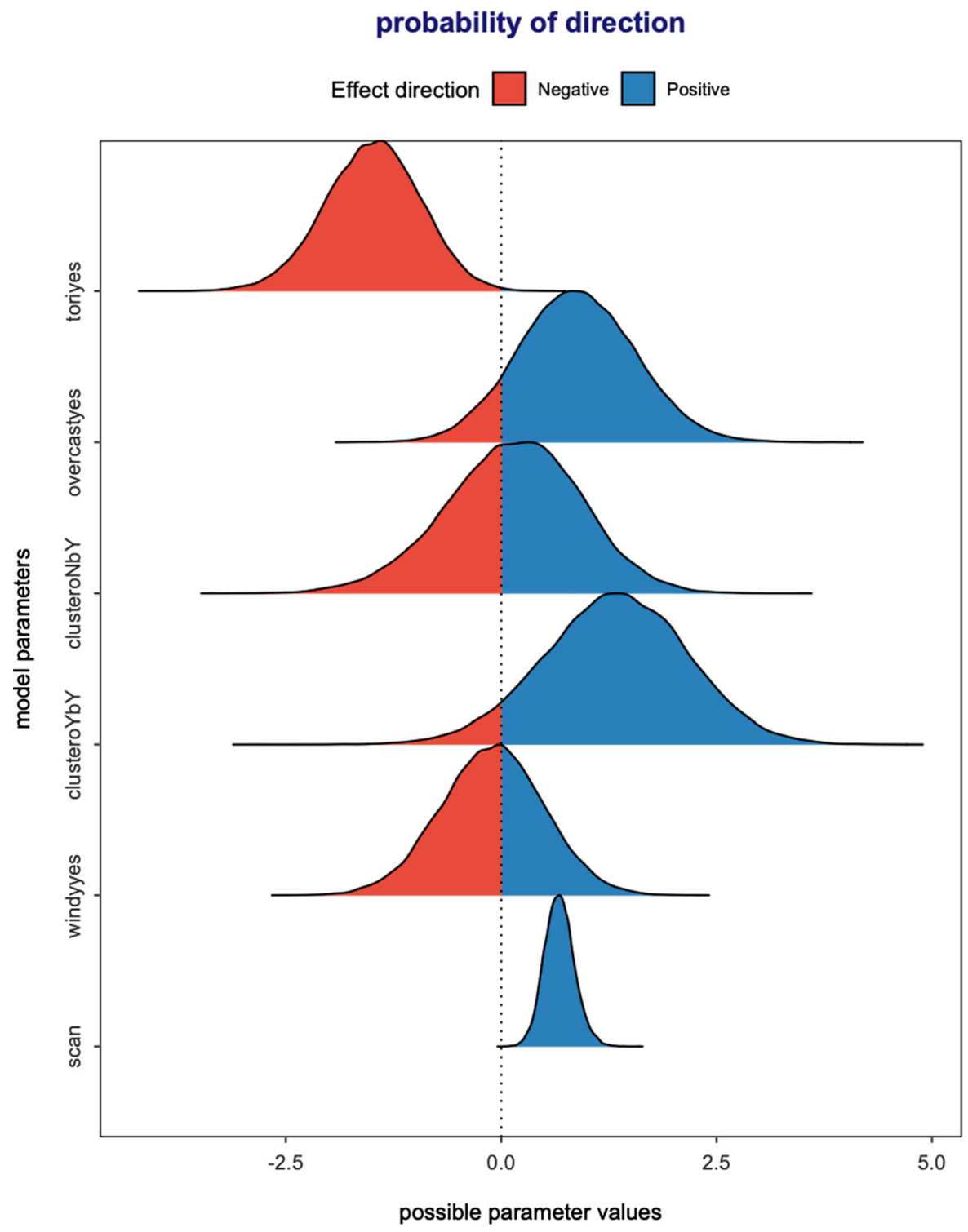

Fig. 4 Probability of direction plot for selected parameters estimated from the best-fit GAMM for the albatross bait/gear contact rate. Polygons show the density summary of the posterior draws and colored given the estimated direction

The estimated marginal means for the tori line effect for the albatross attempt rate sourced from the posterior draws from the best-fit conditional geoGAMM, not shown, was similar to the contact rate results. It was ca. 2 times (95\% HDI 1-4) less likely to have one or more albatross attempt when tori lines were deployed. When conditioned on the offal-bluedyed-bait cluster level, again, the attempt rate is predicted to be lower on sets with tori lines deployed (positive or negative) of the effect or parameter. The proportion of the polygon that does not include zero is a statement about the probability of the proposed direction of the effect

and this effect difference increases with 1 or 2 coapplied mitigation measures-attempt rates were highest when the sets were deployed with both offal and blue-dyed bait, but that co-application of tori lines for those sets moderated that undesirable effect. Importantly, it was apparent that even deploying sets with blue-dyed bait and not offal discharge also increased the albatross attempt rate that was again moderated by co-application of tori lines. 


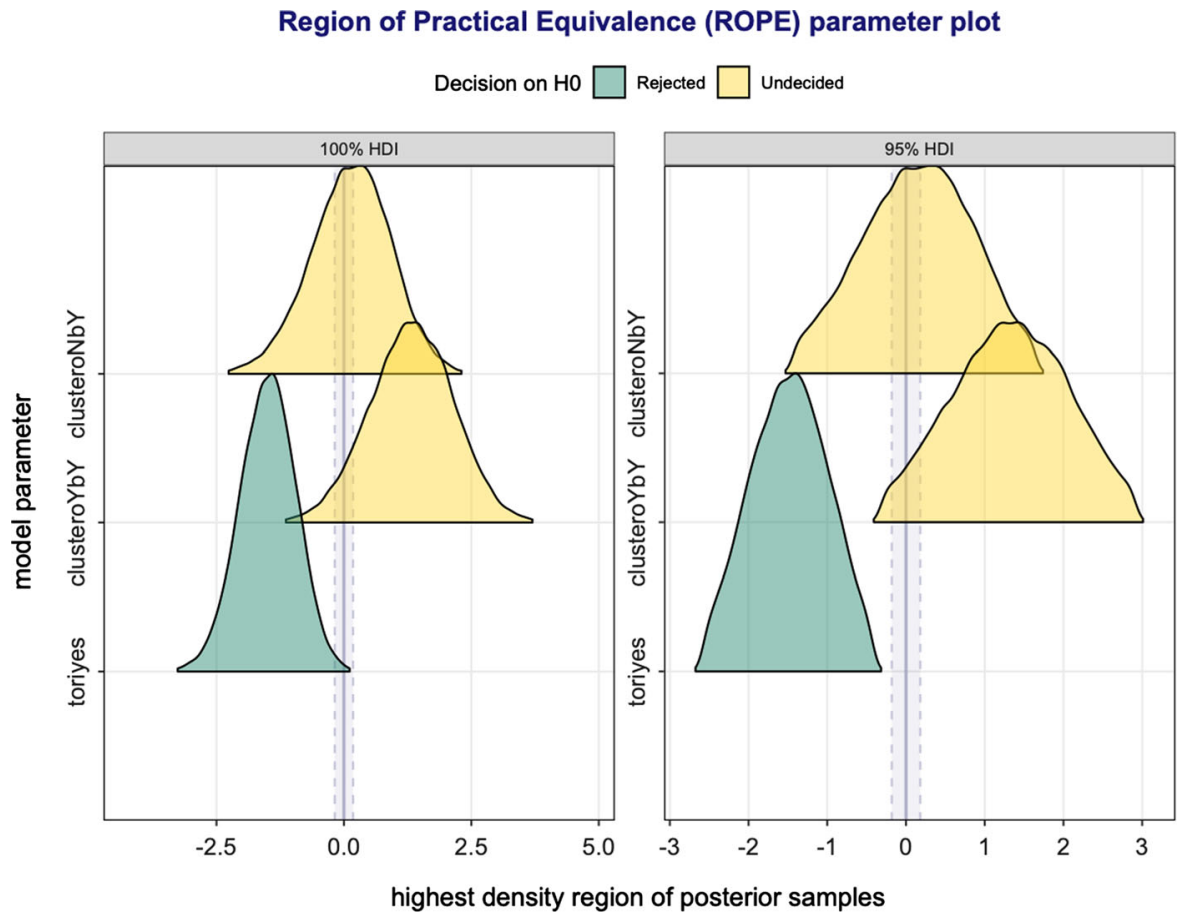

Fig. 5 ROPE-based summary of the significance of the tori line and offal-blue dyed bait cluster effects derived from the best-fit GAMM for the albatross bait/gear contact rate. Panel A shows the effects given a full ROPE based on a $100 \%$ highest posterior

Albatrosses were less likely to be captured when tori-lines were deployed: albatross captures were ca. 1.1 times (95\% HDI: $0.3-2.8$ ) less likely when using tori lines, but captures were too few to support strong inference compared with the contact rate metrics.

\section{Discussion and conclusions}

In any experimental setting it is important to be able conclude that there was an effect, when there really was an effect. And it is equally as important to be able to conclude that there was no effect, when there was in fact no effect. So, we used a Bayesian structured workflow to support robust statistical inference about the efficacy of tori lines as a seabird bycatch mitigation measure in an experimental setting. We found that tori lines did result in substantial reductions in albatross-gear contact rates in our trial for the US central North Pacific tuna longline tuna fishery. In fact, we can be $>99 \%$ sure that this effect occurred in our experimental trial and this is a general finding consistent with previous studies on the application of density interval. Panel B shows the effects given a ROPE based on a $95 \%$ highest posterior density interval. Green polygon indicates a significant effect

tori lines in other pelagic longline fisheries (Yokota et al. 2011; Melvin et al. 2013; Sato et al. 2016; Domingo et al. 2017).

We also found that discharging offal and spent bait during setting might exacerbate and not mitigate seabird catch risk. This is consistent with findings from a demersal longline fishery study that found that higher quantities of offal discharges correlated with higher white-chinned petrel catch rates (Delord et al. 2005). However, it is unclear whether discharging caused the higher bird interaction rates or vice versa. Crew may have discharged offal or spent bait in response to observing high seabird interactions. Discharging offal from processed catch, spent bait and dead discards away from setting and hauling operations may draw scavenging seabirds' attention away from where baited hooks are available and reduce seabird catch rates during that fishing operation (Cherel et al. 1996; McNamara et al. 1999). However, this might be a short-term effect. Based on research conducted in trawl fisheries, increased time between offal discharge events and retention of offal reduced the number of seabirds attending vessels (Abraham 


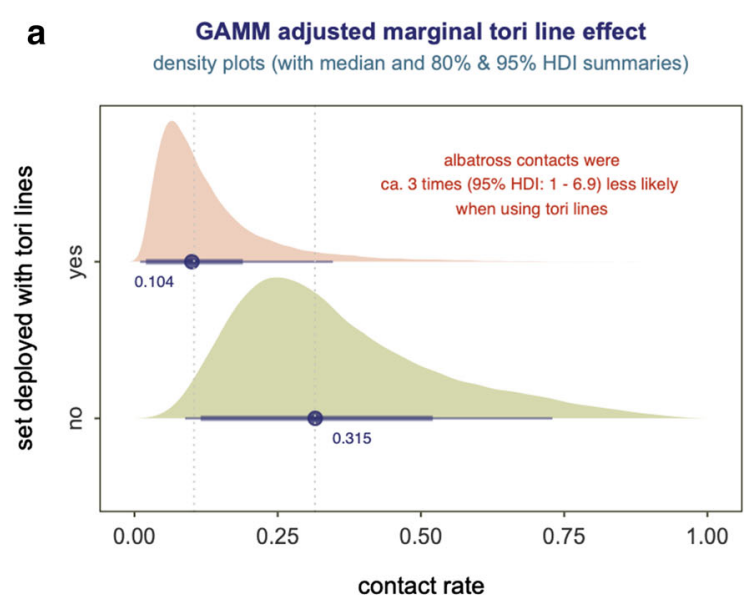

b GAMM adjusted marginal cluster-specific tori line effect (with median \& 95\% HDI summaries)

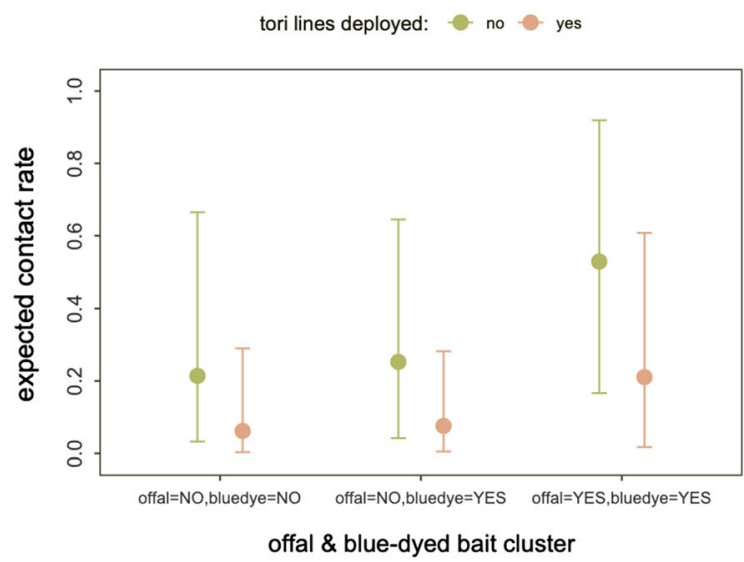

Fig. 6 Summary of the estimated marginal mean tori line effect derived from the best-fit GAMM for the albatross bait/gear contact rate. Panel A shows the estimated tori line effect. Colored polygon shows the density distribution summary, solid $\operatorname{dot}(+$ numeric label $)=$ median estimated of the density polygon, thick horizontal line below each polygon shows the $80 \%$ highest posterior density interval for the density polygon while the thin horizontal line is the 95\% HDI. Panel B shows the estimated tori line effect conditional on offal-blue-dyed-bait treatment cluster - solid dot $=$ estimated median and vertical bar $=95 \%$ highest posterior density interval

et al. 2009; Pierre et al. 2012). The lower the seabird density attending vessels, the lower the seabird catch risk (Gilman et al. 2005; Abraham et al. 2009). Retention might also reduce competitive seabird scavenging behavior and foraging intensity, reducing capture risk (Delord et al. 2005; Gilman et al. 2016). The Hawaii longline fishery may be unique in being required to 'strategically' discharge offal during setting. The tuna RFMOs include either no discharging or strategic discharging as one option (International Commission for the Conservation of Atlantic Tunas 2011; IATTC 2012; IOTC 2012; WCPFC 2018; CCSBT 2020), while CCAMLR (2018) prohibits offal and discard discharging during setting in demersal longline fisheries, consistent with the recommendations of Agreement on the Conservation of Albatrosses and Petrels (ACAP 2019). It is a research priority, with policy implications both locally and internationally, to determine how alternative offal management practices affect long-term seabird catch rates, including effects on factors that may significantly explain seabird catch risk of long-term seabird density at fishing vessels and seabird scavenging and competitive behavior.

The study demonstrated that an EM system can be designed to collect variables that significantly explain seabird catch risk. This included the employment of some of the seabird bycatch mitigation methods that were used during setting in the study (tori lines including streamer line position in relation to baited hooks, blue-dyed bait, offal management), but not branchline weight amount or distance from the hook (leader length), consistent with previous assessments of EM system capabilities (Ames et al. 2005; Piasente et al. 2012; Gilman et al. 2020). The EM system was also capable of enumerating seabirds to the species level during scan counts, which was achieved in some previous EM trials (McElderry et al. 2011; Piasente et al. 2012) but not others (McElderry et al. 2004, 2011), and the environmental factors Beaufort wind force scale and cloud cover. All sets were made during the daytime. Nighttime setting might prevent the EM analyst from consistently or accurately collecting some of these variables (Ames et al. 2005; Piasente et al. 2012). During night, seabird scan count estimates might be more accurate when using thermal or infrared night-vision cameras (Gelman et al. 2014). We explored but determined it was not feasible for the EM analyst to accurately estimate the relative hue, value and chroma of bait due to variable lighting conditions. It was also not feasible for the EM analyst to estimate the duration that baits soaked in blue dye prior to setting due to the camera field of view. After the project was finished, the bullet cameras (GVABL8712) used to record the stern of the vessel were severely corroded. Dome cameras with similar image capabilities may be more suitable. 
Our findings on the efficacy of the tori line design evaluated for the US central North Pacific tuna longline fishery might not be applicable to fisheries that encounter different seabird species complexes. The ca. $50 \mathrm{~m}$-long streamer line aerial section covered $99.7 \%$ of the attempts and contacts by Laysan and black-footed albatrosses. Laysan and black-footed albatrosses have limited diving capacities, typically only making body thrusts to reach prey within about half a meter of the surface (Kezama et al. 2019). Furthermore, unlike in other regions, secondary interactions, where relatively small species of deep-diving seabirds access baited hooks at depth and bring the baited hook to the sea surface where larger seabird species have a second opportunity to access the terminal tackle and become captured (Jimenez et al. 2012; Melvin et al. 2014), is understood to not occur in the US central North Pacific tuna longline fisheries (Gilman et al. 2016).

During the experiment, there was one incident of the tori line's safety line entangling with gear. There were no incidents of tori lines breaking. No safety issues were raised by the fishers related to deploying and retrieving the tori line. Additional research could identify changes to the tori line design that improve its efficacy while remaining practical and safe to use. For instance, alternative colors and materials for the streamers might increase seabird mitigation efficacy (Delord et al. 2005). With over half of observed seabird interactions occurring within $10 \mathrm{~m}$ of the vessel stern, improved tori line protection of bait hooks in this area should be explored, while also considering practicality and safety of alternative tori line designs.

Our findings contribute to evidence-informed seabird conservation management policy-finding tori lines to be an effective management measure to mitigate albatross interactions with this central North Pacific tuna longline fishery, and in highlighting the need for further experimental investigation of 'strategic' offal discharge and blue-dyed bait. More primary, controlled field experiments, as well as syntheses of accumulated research, are needed to disentangle the relative efficacy of the various seabird bycatch mitigation methods provided as options by the tuna RFMOs and recommended by others (International Commission for the Conservation of Atlantic Tunas 2011; IATTC 2012; IOTC 2012; WCPFC 2018; ACAP 2019; CCSBT 2020). Quantitative meta- analytic modelling with significant overall expected effects provides the strongest and most generalizable evidence (Sutton et al. 2000; Evans 2003; Chalmers 2007). Unlike in properly designed experimental studies, observational studies do not experimentally manipulate specific variables and control for others. As a result, estimated effects of individual variables from analyses of observer data are always confounded by other variables. However, during commercial operations, fishers' implementation of bycatch mitigation methods can differ substantially from their implementation during research, which can result in large differences in efficacy (Gilman et al. 2005; Cox et al. 2007). Consequently, in addition to experimental studies, properly designed analyses of observer data that standardize effort by explicitly accounting for potentially significant explanatory variables are also needed to determine whether and why application of mitigation methods perform differently during commercial use so that interventions can be pursued to address any deviations in prescribed application. Meta-analytic syntheses of accumulated research estimate an overall or pooled effect, and if effects vary across studies, they can also identify reasons for between-study heterogeneity. Synthesis research also identifies knowledge gaps, and conversely identifies areas where additional studies are not needed, guiding future research (Chalmers et al. 2014). Due to the larger sample size plus the number of independent studies, correctly designed meta-analytic assessments can provide estimates with increased accuracy over estimates from single studies, with increased statistical power to detect a real effect. By synthesizing estimates from a mixture of independent, small and contextspecific studies, the overall estimated effect from meta-analyses is generalizable and relevant over diverse settings (Nakagawa et al. 2015).

Acknowledgements We are grateful to the captains, crew and owners of the participating fishing vessels Janthina, St. Marianne, St. Damien, Queen Diamond 2, Queen Alina, Golden Phoenix, and Hawaii Ocean. We thank David Goad of Vita Maris, and Daisuke Ochi and Haruka Hayashi of the Japan Fisheries Research and Education Agency for advice on tori line designs and materials. We thank John Wang, U.S. National Marine Fisheries Service, for his contributions to the study. Sean Martin of Pacific Ocean Producers kindly provided access to their warehouse to build tori lines. Lizzie Pearmain of BirdLife International kindly assisted with providing access to albatross distribution data. 
Funding EG, MC and $\mathrm{HN}$ received funding from the Western Pacific Regional Fishery Management Council for this study. This project was supported by the NOAA Cooperative Research Program through NOAA and Council Award NA15NMF4410066, the Joint Institute for Marine and Atmospheric Research, and the Pacific Islands Fisheries Science Center.

Availability of data The fisheries electronic monitoring data used in this study are owned by and are available from the U.S. government agency NOAA Fisheries and restrictions apply to their availability. Under the terms of a nondisclosure agreement with U.S. NOAA that the authors who analyzed the data had to execute, and under Sects. 1905 and 201-209 of Title 18 of the United States Code (referred to as the Trade Secrets Laws and Conflict of Interests Laws, respectively), the authors are prevented from making the U.S. government data publicly available.

Software availability All statistical modeling software used in this study are cited in the Methods section.

\section{Declarations}

Conflict of interest The authors declare that they have no known conflicts or competing interests that influenced the work reported in this paper.

\section{References}

Abraham E, Pierre J, Middleton D, Cleal J, Walker N, Waugh S (2009) Effectiveness of fish waste management strategies in reducing seabird attendance at a trawl vessel. Fish Res 95:210-219. https://doi.org/10.1016/j.fishres.2008.08.014

ACAP (2019) ACAP review and best practice advice for reducing the impact of Pelagic Longline Fisheries on seabirds agreement on the conservation of Albatrosses and Petrels Hobart, Australia

Ames R, Williams G, Fitzgerald S (2005) Using digital video monitoring systems in fisheries: application for monitoring compliance of seabird avoidance devices and seabird mortality in Pacific Halibut Longline Fisheries. NOAA Technical Memorandum NMFS-AFSC-152. Alaska Fisheries Science Center, National Marine Fisheries Service: Seattle

Anderson O, Small C, Croxall J et al (2011) Global seabird bycatch in longline fisheries. Endanger Species Res 14:91-106. https://doi.org/10.3354/esr00347

Baldwin S, Bauer D, Stice E, Rohde P (2011) Evaluating models for partially clustered designs. Psychol Methods 6:149-165. https://doi.org/10.1037/a0023464

Bergh M, Pikitch E, Skalski J, Wallace J (1990) The statistical design of comparative fishing experiments. Fish Res 9:143-163

Boggs C (2001) Deterring albatrosses from contacting baits during swordfish longline sets. In: Melvin E, Parish J (eds)
Seabird Bycatch: Trends, Roadblocks and Solutions. University of Alaska Sea Grant, Anchorage, pp 79-94

Brothers N, Cooper J, Lokkeborg S (1999) The incidental catch of seabirds by Longline Fisheries: worldwide review and technical guidelines for mitigation. FAO Fisheries Circular 937. Food and Agriculture Organization of the United Nations, Rome

Bürkner P (2017) brms: an R package for Bayesian multilevel models using Stan. J Stat Softw 80:1-28. https://doi.org/10. 18637/jss.v080.i01

Candlish J, Teare M, Dimairo M, Flight L, Mandefield L, Walters S (2018) Appropriate statistical methods for analysing partially nested randomised controlled trials with continuous outcomes: a simulation study. BMC Med Res Methodol 18:105. https://doi.org/10.1186/s12874-0180559-X

Carpenter B, Gelman A, Hoffman M et al (2017) Stan: a probabilistic programming language. J Stat Softw 76:1-32

CCAMLR (2018) Minimisation of the incidental mortality of seabirds in the course of Longline Fishing or Longline Fishing Research in the convention area. Conservation Measure 25-02. Commission for the Conservation of Antarctic Marine Living Resources, Hobart, Australia

CCSBT (2020) Resolution to align CCSBT's ecological related species measures with those of other Tuna RFMOs. Commission for the Conservation of Southern Bluefin Tuna, Hobart, Australia

Chalmers I (2007) The lethal consequences of failing to make use of all relevant evidence about the effects of medical treatments: the need for systematic reviews. In: Rothwell P (ed) Treating Individuals: from randomized trials to personalised medicine. Elsevier, London, pp 37-58

Chalmers I, Bracken M, Djulbegovic B et al (2014) How to increase value and reduce waste when research priorities are set. The Lancet 383:156-165

Cherel Y, Weimerskirch H, Duhamel G (1996) Interactions between longline vessels and seabirds in Kreguelen waters and a method to reduce seabird mortality. Biol Conserv 75:63-70. https://doi.org/10.1016/0006-3207(95)00037-2

Chordata (2019) Open source electronic monitoring for commercial fisheries. https://pt.chrdta.com/em/ and https:// bitbucket.org/fisherieselectronicmonitoring/. Chordata, Juneau, Alaska

Congdon P (2003) Applied Bayesian modelling. Wiley

Cox T, Lewison R, Zydelis R, Crowder L, Safina C, Read A (2007) Comparing effectiveness of experimental and implemented bycatch reduction measures: the ideal and the real. Conserv Biol 21:1155-1164

Davies T, Jonsen I (2011) Identifying nonproportionality of fishery-independent survey data to estimate population trends and assess recovery potential for cusk (Brosme brosme). Can J Fish Aquat Sci 68:413-425

Delord K, Gasco N, Weimerskirch H, Barbraud C, Micol T (2005) Seabird mortality in the Patagonian toothfish longline fishery around Crozet and Kerguelen Islands, 2001-2003. CCAMLR Sci 12:53-80

Dias M et al (2019) Threats to seabirds: a global assessment. Bio Cons 237:525-537

Domingo A, Jiménez S, Abreu M, Forselledo R, Yates O (2017) Effectiveness of tori line use to reduce seabird bycatch in pelagic longline fishing. PLoS ONE 12:e0184465 
Dorai-Raj S (2014) binom: Binomial confidence intervals for several parameterizations. $\mathrm{R}$ package version 1.1-1. https://CRAN.R-project.org/package=binom

Evans D (2003) Hierarchy of evidence: a framework for ranking evidence evaluating healthcare interventions. J Clin Nurs 12:77-84

Fahrmeir L, Lang S (2001) Bayesian inference for generalised additive mixed models based on Markov random field priors. Appl Stat 50:201-220

Gabry J, Simpson D, Vehtari A, Betancourt M, Gelman A (2019) Visualization in Bayesian workflow. J R Soc Ser A 182:1-14

Gelfand A, Schliep E (2016) Spatial statistics and Gaussian processes: a beautiful marriage. Spat Stat 18(Part A):86-104

Gelman A, Hill J (2007) Data analysis using regression and multilevel/hierarchical models. Cambridge University Press, New York

Gelman A, Hwang J, Vehtari A (2014) Understanding predictive information criteria for Bayesian models. Stat Comput 24:997-1016

Gilman E, Boggs C, Brothers N (2003) Performance assessment of an underwater setting chute to mitigate seabird bycatch in the Hawaii pelagic longline tuna fishery. Ocean Coast Manag 46:985-1010

Gilman E, Brothers N, Kobayashi D (2005) Principles and approaches to abate seabird bycatch in longline fisheries. Fish Fish 6:35-49

Gilman E, Chaloupka M, Wiedoff B, Willson J (2014) Mitigating seabird bycatch during hauling by pelagic longline vessels. PLoS ONE 9:e84499

Gilman E, Chaloupka M, Peschon J, Ellgen S (2016) Risk factors for seabird bycatch in a pelagic longline tuna fishery. PLoS ONE 11:e0155477

Gilman E, Castejon V, Loganimoce E, Chaloupka M (2020) Capability of a pilot fisheries electronic monitoring system to meet scientific and compliance monitoring objectives. Mar Policy. https://doi.org/10.1016/j.marpol.2019.103792

Goad D (2017) Tori line designs for small longline vessels. New Zealand Department of Conservation, Wellington

Goad D, Debski I (2017) Tori line designs and specifications for small Pelagic Longline Vessels. WCPFC-SC13-2017/EBWP-08 Rev 1. Western and Central Pacific Fisheries Commission, Kolonia, Federated States of Micronesia

Gray C, Kennelly S (2018) Bycatches of endangered, threatened and protected species in marine fisheries. Rev Fish Biol Fisheries 28:521-541

IATTC (2012) Resolution to mitigate the impact on seabirds of fishing for species covered by the IATTC. Resolution C-11-02. Inter-American Tropical Tuna Commission, La Jolla, USA

ICCAT (2011) Supplemental recommendation by ICCAT on reducing incidental by-catch of seabirds in ICCAT Longline Fishery. Recommendation 11-09. International Commission for the Conservation of Atlantic Tunas, Madrid

IOTC (2012) Resolution 12/06 on reducing the incidental bycatch of seabirds in Longline Fisheries. Resolution 12/06. Indian Ocean Tuna Commission, Mahe, Seychelles

IUCN (2021) The IUCN Red List of Threatened Species. Version 2020-3. www.iucnredlist.org, ISSN 2307-8235.
International Union for the Conservation of Nature, Gland, Switzerland

Japan Ministry of Agriculture, Forestry and Fisheries (2008) Restrictions of Fishing Gear Specified by the Minister of Agriculture, Forestry, and Fisheries, Pursuant to the Provisions of Article 20-2 of the Ministerial Ordinance Regulating Specific Fisheries Permitted by the Minister. Minister of Agriculture, Forestry, and Fisheries Public Notice No.1193, July 25 (2008) In Japanese. Ministry of Agriculture, Forestry and Fisheries, Tokyo, Japan

Jensen S, Schaarschmidt F, Onofri A, Ritz C (2018) Experimental design matters for statistical analysis: how to handle blocking. Pest Manag Sci 74:523-534

Jimenez S, Domingo A, Abreu M, Brazeiro A (2012) Bycatch susceptibility in pelagic longline fisheries: Are albatrosses affected by the diving behaviour of medium-sized petrels? Aquat Conserv 22:436-445

Jimenez S, Domingo A, Winder $\mathrm{H}$ et al (2020) Towards mitigation of seabird bycatch: large-scale effectiveness of night setting and tori lines across multiple pelagic longline fleets. Bio Cons 247:108642

Kammann E, Wand M (2003) Geoadditive models. Appl Stat 52:1-18

Katsumata N, Okamoto K, Oshima K, Ochi D (2019) Research update about the effective design of Tori line for Japanese Small-scale Fleet in the North Pacific. WCPFCSC15-2019/EB-WP-06. Western and Central Pacific Fisheries Commission, Kolonia, Federated States of Micronesia

Kay M (2020a) tidybayes: tidy data and geoms for Bayesian models. R package version 2(1):1. https://doi.org/10.5281/ zenodo.1308151

Kay M (2020b) ggdist: visualizations of distributions and uncertainty. $\mathrm{R}$ package version 2.3.0. https://mjskay. github.io/ggdist/

Kelter R (2020) Analysis of Bayesian posterior significance and effect size indices for the two-sample t-test to support reproducible medical research. BMC Med Res Methodol 20:88. https://doi.org/10.1186/s12874-020-00968-2

Kezama K, Harada T, Deguchi T, Suzuki H, Watanuki Y (2019) Foraging behavior of black-footed albatross Phoebastria nigripes rearing chicks on the Ogasawara Islands. Ornithol Sci 18:27-37

Kruschke J, Liddell T (2018) The Bayesian new statistics: hypothesis testing, estimation, meta-analysis, and power analysis from a Bayesian perspective. Psychon Bull Rev 25:178-206

Lemoine N (2019) Moving beyond noninformative priors: why and how to choose weakly informative priors in Bayesian analyses. Oikos 128:912-928

Lenth R (2016) Least-squares means: the R package lsmeans. J Stat Softw 69:1-33

Lenth R (2020) emmeans: estimated marginal means, aka leastsquares means. R package version 1.5.2-1. https://CRAN. R-project.org/package=emmeans

Makowski D, Ben-Shachar M, Lüdecke D (2019) bayestestR: describing effects and their uncertainty, existence and significance within the Bayesian framework. J Open Source Softw 4:1541. https://doi.org/10.21105/joss.01541

McElderry H, Schrader J, McCullough D, Illingworth J, Fitzgerald S, Davis S (2004) Electronic monitoring of 
seabird interactions with trawl third-wire cables on trawl vessels-a pilot study. NOAA Technical Memorandum NMFS-AFSC-147. Alaska Fisheries Science Center, National Marine Fisheries Service, Seattle

McElderry H, Beck M, Pria M, Anderson S (2011) Electronic monitoring in the New Zealand inshore trawl fishery: a pilot study. DOC Marine Conservation Services Series 9. Department of Conservation, Wellington

McNamara B, Torre L, Kaaialii G (1999) Hawaii Longline seabird mortality mitigation project. Western Pacific Regional Fishery Management Council, Honolulu

Melvin E, Guy T, Read L (2013) Reducing seabird bycatch in the South African joint venture tuna fishery using birdscaring lines, branch line weighting and nighttime setting of hooks. Fish Res 147:72-82

Melvin E, Guy T, Read L (2014) Best practice seabird bycatch mitigation for pelagic longline fisheries targeting tuna and related species. Fish Res 149:5-18

Nakagawa S, Poulin R, Mengersen K, Reinhold K, Engqvist L, Lagisz M, Senior A (2015) Meta-analysis of variation: ecological and evolutionary applications and beyond. Methods Ecol Evol 6:143-152

New Zealand Ministry for Primary Industries (2020) Fisheries (Seabird Mitigation Measures-Surface Longlines) Circular (No. 2) (2019) Notice Number MPI 1111. Ministry for Primary Industries, Wellington

Pedersen T (2020) patchwork: the composer of plots. R package version 1.1.0. https://CRAN.R-project.org/package= patchwork

Phillips R, Gales R, Baker G et al (2016) The conservation status and priorities for albatrosses and large petrels. Bio Cons 201:169-183

Piasente M, Stanley B, Timmiss T, McElderry H, Pria M, Dyas M (2012) Electronic onboard monitoring pilot project for the eastern tuna and billfish fishery. FRDC Project 2009/048. ST-IP-05. Kolonia, Federated States of Micronesia: Western and Central Pacific Fisheries Commission

Pierre J (2018) Using electronic monitoring imagery to characterize protected species interactions with commercial fisheries: a primer and review. JPEC Ltd, Lower Hutt, New Zealand

Pierre J, Abraham E, Richard Y, Cleal J, Middleton D (2012) Controlling trawler waste discharge to reduce seabird mortality. Fish Res 131:30-38

South Africa Department of Agriculture, Forestry and Fisheries (2019) Section B. Permit Conditions: Large Pelagic Longline Fishery. Fishing Season: 2019/2020. Department of Agriculture, Forestry and Fisheries, Pretoria

Sato N, Katsumata N, Yokota K, Uehara T, Fusejima I, Minami $\mathrm{H}$ (2016) Tori-lines with weighted branch lines reduce seabird bycatch in eastern South Pacific longline fishery. Aquat Conserv Mar Freshwat Ecosyst 26:95-107

Searle S, Speed F, Milliken G (1980) Population marginal means in the linear model: an alternative to least squares means. Am Stat 34:216-221

Sutton A, Abrams K, Jones D, Sheldon T, Song F (2000) Methods for meta-analysis in medical research. Wiley, New York

Tuyl F, Gerlach R, Mengersen K (2008) Comparison of BayesLaplace, Jeffreys, and other priors: the case of zero events. Am Stat 62:40-44

Uruguay Direccion Nacional de Recursos Acuqticos (2015) Revision de Planes de Accion Nacional para la conservacion de Aves Marinas y Condrictios en las Pesquerias Uruguayas. Direccion Nacional de Recursos Acuqticos, Ministerio de Ganaderia Agricultura y Pesca, Montevideo

Vehtari A, Gelman A, Gabry J (2017) Practical Bayesian model evaluation using leave-one-out cross-validation and WAIC. Stat Comput 27:1413-1432. https://doi.org/10. 1007/s11222-016-9696-4

WCPFC (2018) Conservation and Management Measure to Mitigate the Impact of Fishing for Highly Migratory Fish Stocks on Seabirds. CMM 2018-03. Western and Central Pacific Fisheries Commission, Kolonia, Federated States of Micronesia

Wickham H (2016) ggplot2: elegant graphics for data analysis, 2nd edn. Springer, New York

Wood S (2006) Generalized additive models: an introduction with R. Chapman and Hall/CRC, Boca Raton

WPRFMC (2020) Annual Stock Assessment and Fishery Evaluation Report for U.S. Pacific Island Pelagic Fisheries Ecosystem Plan 2019. Western Pacific Regional Fishery Management Council, Honolulu

Yao Y, Vehtari A, Simpson D, Gelman A (2018) Using stacking to average Bayesian predictive distributions (with discussion). Bayesian Anal 13:917-1003. https://doi.org/10. 1214/17-BA1091

Yokota K, Minami H, Kiyota M (2011) Effectiveness of torilines for further reduction of incidental catch of seabirds in pelagic longline fisheries. Fish Sci 77:479-485. https://doi. org/10.1007/s12562-011-0357-4

Zeileis A, Fisher J, Hornik K, Ihaka R, McWhite C, Murrell P, Stauffer R, Wilke C (2020) colorspace: a toolbox for manipulating and assessing colors and palettes. J Stat Softw 96:1-4. https://doi.org/10.18637/jss.v096.i01

Publisher's Note Springer Nature remains neutral with regard to jurisdictional claims in published maps and institutional affiliations. 